\title{
Comparison of three different protocols of alkaloid extraction from Glaucium corniculatum plant
}

\author{
Fatma Gonca Kocanci (iD) 1,*, Serap Nigdelioglu Dolanbay (iD)2, Belma Aslim (iD)2
}

\author{
${ }^{1}$ Alaaddin Keykubat University, Vocational High School of Health Services, Department of Medical Laboratory \\ Techniques, Alanya, Antalya, Turkiye \\ ${ }^{2}$ Gazi University, Faculty of Science, Department of Biology, Ankara, Turkiye
}

\begin{abstract}
Alkaloids, plant secondary metabolites, have a wide variety of biological effects. For this reason, the extraction of alkaloids from plants is of strategic importance. Different extraction protocols for the extraction of alkaloids from plants have been described by many authors. The objective of this study was to compare the efficacy of three different protocols for the extraction of alkaloids from Glaucium corniculatum. This article compares the Soxhlet and ultrasonication protocol, used in previous studies, to a modified Soxhlet protocol. While the alkaloid amount in the extract was determined by the spectrophotometric method, the qualitative estimation of the compounds in the extract was determined by Gas chromatograph-Mass spectrometer (GCMS). The alkaloid amount and diversity in the extract, obtained through the recommended modified Soxhlet protocol, were higher than that of any extract obtained through other protocols. Thus, a new modified alkaloid extraction protocol was established, which is better than the other protocol.
\end{abstract}

\section{ARTICLE HISTORY}

Received: Aug. 08, 2021

Revised: Jan. 16, 2022

Accepted: Feb. 03, 2022

\section{KEYWORDS}

Alkaloid,

Extraction,

Glaucium corniculatum,

Ultrasonication,

Soxhlet

\section{INTRODUCTION}

Plant secondary metabolites have become the focus of many studies due to their therapeutic effects. For this reason, extraction protocols that allow the extraction of secondary metabolites have gained importance. One of the most important groups of secondary metabolites is alkaloids. These are organic compounds containing nitrogen and heterocyclic rings and having significant pharmacodynamic activity even in very small doses (Hesse, 2002). About $20 \%$ of plant species contain alkaloids, which play a role in defense against herbivores and pathogens. Archaeological and historical records reveal that alkaloid-containing plants have been used as empirical drug sources since ancient times (Amirkia \& Heinrich, 2014). Alkaloids have a wide variety of biological effects, including anti-microbial, anti-diabetic, anti-ulcer, anti-viral, antiinflammatory, anti-arrhythmic, anti-oxidant, anti-diarrheal , anti-mutagen, hypolipidemic, antitumor and neuroprotective (Cushnie et al., 2014; Chaves et al., 2016; Yu et al., 2005). The extraction of alkaloids with high yield and variety is of strategic importance due to the foregoing medicinal properties. The plant selected for this study is G. corniculatum, the subject matter of

\footnotetext{
"CONTACT: Fatma Gonca Kocanci $\square$ goncaok@gmail.com Alaaddin Keykubat University, Vocational High School of Health Services, Department of Medical Laboratory Techniques, Alanya, Antalya, Turkiye
} 
the study, is rich in alkaloid content (Doncheva et al., 2014; Kintsurashvili \& Vachnadze, 2000; Phillipson et al., 1981; Shafiee et al., 1985). Therefore, it is a good source of alkaloids.

Recent advancements in Soxhlet and ultrasonic extractions have increased the interest in the evaluation and optimization of the extraction of alkaloids. These techniques tend to be accurate and generally practicable and therefore, can replace the old standard protocols used for the extraction of alkaloids. Soxhlet method is one of the most widely used methods for the extraction of total alkaloids. This is mainly because it is very easy to carry out, and a formally recognized method used for the determination of a wide range of alkaloid content. In the Soxhlet extraction method, the solvent contacts the soluble sample directly, and the bioactive compounds in the sample are extracted directly into the solvent (Webster, 2006). KhamtacheAbderrahim et al. (2016) recommended a Soxhlet protocol for the extraction of alkaloids from plants (Khamtache-Abderrahim et al., 2016).

Ultrasonic extraction involves the transfer of bioactive components from a permeable solid matrix to the solvent through sound energy (Webster, 2006). Recently, innovative extractions, such as ultrasound extraction, have been shown to be an alternative to conventional procedures for the extraction of bioactive alkaloids from plants because they are more efficient and faster than conventional procedures. Moreover, they are more ecologically friendly, and solvents used therein are less toxic (Desgrouas et al., 2014). Existing studies have concluded that ultrasonic energy is absolutely beneficial for the extraction of alkaloids from plants, provided that ultrasound is sufficiently intense and correctly applied (Demaggio \& Lott, 1964). Sarikaya et al. (2014) proposed a protocol based on ultrasonic method for the extraction of alkaloids from plants by methanolic extraction. Application time, temperature and chemicals affect the extraction yield and variety both in Soxhlet protocol and ultrasonication protocol (Sarikaya et al., 2014).

This article compared two protocols, recommended by Khamtache-Abderrahim et al. and Sarikaya et al. for the extraction of alkaloids, to a modified Soxhlet protocol. After extraction, the total amount of alkaloids in three protocols was determined using spectroscopic method. The alkaloid yields of these protocols were also determined. In addition, the alkaloid diversity of the extracts, obtained by different protocols, was analyzed by GC-MS.

\section{MATERIAL and METHODS}

\subsection{Plant Material}

G. corniculatum (L) RUD. subsp. refractum (NAB.) CULLEN was collected from Beypazari district in the northwest of Ankara on 27.07.2015 by Prof. Dr. Zeki Aytaç. The aerial parts of the plant were dried and powdered. Gazi University herbarium material number of this plant is ZA10700.

\subsection{Total Alkaloid Extraction}

Three total alkaloid extraction protocols were evaluated in this study. For protocol A, B and C, the G. corniculatum was subjected to different extraction protocols.

Protocol A: Extraction by Soxhlet method

$15 \mathrm{~g}$ of powdered plant samples were separately extracted with $150 \mathrm{~mL}$ of methanol solvent for 4 hours in a Soxhlet apparatus (LabHeat). The solvent was removed in the evaporator (Heidolph Laborator 4000) at controlled temperature $\left(60-100{ }^{\circ} \mathrm{C}\right)$ and low pressure. The plant extracts were taken up in $10 \mathrm{~mL}$ of hydrochloric acid $(\mathrm{HCl})(2.5 \%)$ and $150 \mathrm{~mL}$ of diethyl ether $\left(\left(\mathrm{C}_{2} \mathrm{H}_{5}\right)_{2} \mathrm{O}\right)$ was added to dissolve the oils in the extracts. The $\mathrm{pH}$ of the aqueous acid solution was adjusted to 8 with ammonium hydroxide $\left(\mathrm{NH}_{4} \mathrm{OH}\right)$. Then $150 \mathrm{~mL}$ of dichloromethane $\left(\mathrm{CH}_{2} \mathrm{Cl}_{2}\right)$ was added. The extracts were dried over magnesium sulphate $\left(\mathrm{MgSO}_{4}\right)$. The solvent was evaporated at controlled temperature $\left(60-100{ }^{\circ} \mathrm{C}\right)$ and using a low pressure evaporator 
(Heidolph Laborat 4000) to obtain the crude solids of the total alkaloids. The residue was stored at $+4{ }^{\circ} \mathrm{C}$ for use in experimental studies (Khamtache-Abderrahim et al., 2016).

Protocol B: Extraction by ultrasonication method

$1 \mathrm{~g}$ of powdered plant samples were separately sonicated for 30 minutes with $10 \mathrm{~mL}$ of methanol solubilizer. The liquid portion was filtered, and the solvent removed at the controlled temperature $\left(40{ }^{\circ} \mathrm{C}\right)$ and using a low pressure evaporator. The plant extracts were taken up in $10 \mathrm{~mL}$ of sulfuric acid $(2 \%)$ and passed through $3 \times 50 \mathrm{~mL}$ of $\left(\mathrm{C}_{2} \mathrm{H}_{5}\right)_{2} \mathrm{O}$. It was separated from the oil in the separation funnel. The $\mathrm{pH}$ of the aqueous acid solution was adjusted to 9 with $\mathrm{NH}_{4} \mathrm{OH} .3 \times 50 \mathrm{~mL}$ chloroform was then added. The extract was dried in sodium sulphate and evaporated in a rotary evaporator under controlled temperature $\left(40{ }^{\circ} \mathrm{C}\right)$ and low pressure. The residue was stored at $+4{ }^{\circ} \mathrm{C}$ for use in experimental studies (Sarikaya et al., 2014).

Protocol C: Recommended modified Soxhlet method

$10 \mathrm{~g}$ of powdered plant sample was extracted with $150 \mathrm{~mL}$ of methanol solvent in a Soxhlet apparatus (LabHeat) for 8 hours. The solvent was removed at the controlled temperature (40 ${ }^{\circ} \mathrm{C}$ ) and using a low pressure evaporator. The plant extracts were taken up in $10 \mathrm{~mL}$ of sulfuric acid $(2 \%)$ and passed through $3 \times 50 \mathrm{~mL}$ of $\left(\mathrm{C}_{2} \mathrm{H}_{5}\right)_{2} \mathrm{O}$. It was separated from the oil in the separation funnel. The $\mathrm{pH}$ of the aqueous acid solution was adjusted to 9 with $\mathrm{NH}_{4} \mathrm{OH} .3 \times 50$ $\mathrm{mL}$ chloroform was then added. The chloroform extract was dried in sodium sulphate and evaporated in a rotary evaporator under controlled temperature $\left(40{ }^{\circ} \mathrm{C}\right)$ and low pressure. The residue was stored at $+4{ }^{\circ} \mathrm{C}$ for use in experimental studies.

Spectroscopic method and GC-MS were used to compare the amount, ratio and variety of alkaloid obtained by the different protocols.

\subsection{Determination of Total Alkaloids Using Spectroscopic Methods}

Briefly, bromocresol green (BCG) solution was prepared by heating $69.8 \mathrm{mg}$ BCG (SigmaAldrich, Italy) with $3 \mathrm{ml}$ of $2 \mathrm{~N} \mathrm{NaOH}$ and $5 \mathrm{ml}$ distilled water until completely dissolved and the solution was diluted to $1000 \mathrm{ml}$ with distilled water. $1 \mathrm{mg}$ of plant extract was dissolved in $1 \mathrm{~mL}$ of $\mathrm{HCl}(\mathrm{pH} 2.5)$. Then, $5 \mathrm{~mL}$ of bromocresol green solution $(0.04 \%)$ and $5 \mathrm{~mL}$ of phosphate buffer $(\mathrm{pH} 4.7)$ was added to the extract solution which was transferred to a separation funnel. The mixture was shaken with $5 \mathrm{~mL}$ chloroform. A set of reference standard solutions of boldine ( 25 to $250 \mu \mathrm{g} / \mathrm{mL}$ ) were prepared. The yellow complex in chloroform was finally recovered and the absorbance at $470 \mathrm{~nm}$ was measured against blank (Novelli et al., 2014). The experiment was performed in three replicates and 10 parallels (Novelli et al., 2014).

\subsection{Gas Chromatograph-Mass Spectrometer (GC-MS) Analysis}

Compound analyses were performed by employing GC-MS using Thermo GC -Trace Ultra Ver 2.0 Thermo MS DSQ II (Thermo Fisher Scientific, San Jose, CA, USA) instrument at Ege University Faculty of Pharmacy Pharmaceutical Sciences Research Centre. The temperature conditions followed the program: The initial temperature was $100{ }^{\circ} \mathrm{C}$. It was increased from $100{ }^{\circ} \mathrm{C}$ to $180^{\circ} \mathrm{C}$ at the rate of $15^{\circ} \mathrm{C}$ per minute. It was increased from $180{ }^{\circ} \mathrm{C}$ to $300{ }^{\circ} \mathrm{C}$ at the rate of $5{ }^{\circ} \mathrm{C}$ per minute. Then the temperature was held at $300{ }^{\circ} \mathrm{C}$ for 10 minutes. The injector temperature was $250{ }^{\circ} \mathrm{C}$. Helium was used as the carrier gas at a flow rate of $0.8 \mathrm{~mL} / \mathrm{min}$. HP$5 \mathrm{MS}$ column $(30 \mathrm{~m} \times 0.25 \mathrm{~mm} \times 0.25 \mu \mathrm{m})$ was used. The spectra of chromatographic peaks were investigated using Xcalibur (version 2.07, Thermo Fisher Scientific, San Jose, CA, USA). Compounds were defined by comparing the mass spectral fragmentation with the standard reference spectra of the Wiley $7 \mathrm{~N}$ library database (Kaya et al., 2017). 


\subsection{Statistical Analysis}

Plant uptake was repeated three times for each sample and the average of the three replications was calculated. Data were analyzed with the use of SPSS software (version 21.0) using the oneway ANOVA test. Values are shown as mean \pm standard deviation (SD). Statistical significance was taken at a $p$ value $<0.01$.

\section{RESULTS}

\subsection{Extract and Alkaloid Amount, and Alkaloid Yield}

The extract amount from $1 \mathrm{~g}$ plant, the alkaloid amount in $1 \mathrm{~g}$ extract and the alkaloid yield of the dry plant are shown in Table 1. According to the results, the highest alkaloid content (153 $\pm 6 \mathrm{mg}$ alkaloid/g extract) and the highest alkaloid yield (0.765 mg alkaloid/g dry plant) in the dry plant were obtained through Protocol C. In Protocols A and B, a higher amount of extract was obtained than Protocol C, although the amount of alkaloid in the extract was lower than the amount in Protocol C. The extract amount, obtained in Protocol B, was statistically significant at a level of 0.01 compared to the extract amount obtained in Protocols $\mathrm{A}$ and $\mathrm{C}\left({ }^{*} p<0.01\right)$. The difference between the protocols of total alkaloid extract was also explained statistically. A statistically significant difference was found between Protocol $\mathrm{C}$ and other protocols at the level of $0.01\left({ }^{\#} p<0.01\right)$ (Table 1$)$.

Table 1. Amount of extract and alkaloid, and the alkaloid yield of G. corniculatum.

\begin{tabular}{ccccc}
\hline Protocols & $\begin{array}{c}\text { Extract amount } \\
\text { (mg extract/g plant) }\end{array}$ & & $\begin{array}{c}\text { Alkaloid amount } \\
\text { (mg alkaloid/g } \\
\text { extract) }\end{array}$ & $\begin{array}{c}\text { Alkaloid yield } \\
\text { (mg alkaloid/g } \\
\text { plant) }\end{array}$ \\
\cline { 1 - 3 } \cline { 5 - 6 } \cline { 4 - 5 } \cline { 4 - 5 } $\mathrm{B}^{*}$ & $7 \pm 1$ & & $71 \pm 2$ & 0.355 \\
$\mathrm{C}^{\#}$ & $41 \pm 2$ & $5 \pm 0$ & $40 \pm 4$ & 0.200 \\
\hline
\end{tabular}

${ }^{*} p<0.01$ difference between protocols in terms of the amount of extract

${ }^{\#} p<0.01$ difference between protocols in terms of the amount of alkaloid

\subsection{Alkaloid Diversity}

The alkaloid diversity of alkaloid extracts, obtained from G. corniculatum by different extraction protocols, was determined by GC-MS method. GC-MS chromatograms of the extracts are shown in Figure 1. Six different peaks were identified in the chromatogram of the extract in Protocol A but only one of them was alkaloid. The ratio of alkaloids, obtained through Protocol A, was 7.6\%; and non-alkaloid compounds were 92.4\% (RT:22.34: 6H-

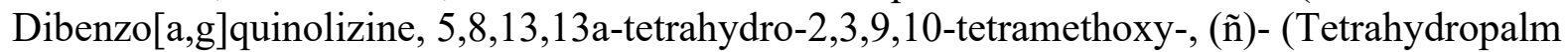
atine) (alkaloid), RT:24.72, 30.26 and 31.18: 9-Hexadecenoic acid, eicosyl ester, (Z) (Fatty acid), RT:34.65 and 35.93: Quercetin 7,3',4'-trimethoxy (flavone)). Twelve different peaks were identified in GC-MS chromatogram of Extract B, but only two of them were alkaloid (RT:6.09: Phenol, 2,6-bis(1,1-dimethylethyl)-4-methyl- (CAS) (Phenol), RT:8.07 and 11.10 Trans-2-phenyl-1,3-dioxolane-4-methyl octadec-9,12,15-trienoate (Phenol), RT:11.18 and 18.26: Quercetin 7,3',4'-trimethoxy (flavone), RT:13.52: Isochiapin B (Terpenoid), RT:14.19: [1,3]Benzodioxolo[5,6-e][2]benzazecin-14(6H)-one, 5,7,8,15-tetrahydro-3,4-dimethoxy-6-me thyl- (Allocryptopine) (alkaloid), RT:24.41: 9,12,15-Octadecatrienoic acid, 2,3-bis[(trimethyl silyl)oxy]propyl ester, (Z,Z,Z)- (fatty acid) RT:26:54: (+)-Canadine (alkaloid), RT:31.56: 9Hexadecenoic acid, eicosyl ester, (Z) (Fatty acid), RT: 32.39 and 33.83: 1,1,3,3,5,5,7,7,9,9,11,11-Dodecamethyl-hexasiloxane (Siloxane derivative)) (Nigdelioglu Dolanbay et al., 2021). The ratio of alkaloid compounds was $77.0 \%$; and non-alkaloid compounds were $23 \%$. Three alkaloid peaks were identified in the chromatogram of the extract obtained by the modified Soxhlet protocol. The ratio of alkaloids in Protocol $\mathrm{C}$ was $100 \%$ 
(RT:24.45: 6H-Dibenzo[a,g]quinolizine, 5,8,13,13a-tetrahydro-2,3,9,10-tetramethoxy-, (ñ)- ( Tetrahydropalmatine) (alkaloid), RT: 26.58: Tetrahydroberberine N-oxide (Canadine) (alkaloi d), RT: 26.88: [1,3]Benzodioxolo[5,6-e][2] benzazecin-14(6H)-one, 5,7,8,15-tetrahydro-3,4-di methoxy-6-methyl- (Allocryptopine) (alkaloid)).

Figure 1. GC-MS chromatograms of total alkaloid extracts obtained from G. corniculatum by Soxhlet (A), ultrasonication (B), and recommended modified Soxhlet (C) protocols (Nigdelioglu Dolanbay et al., 2021).
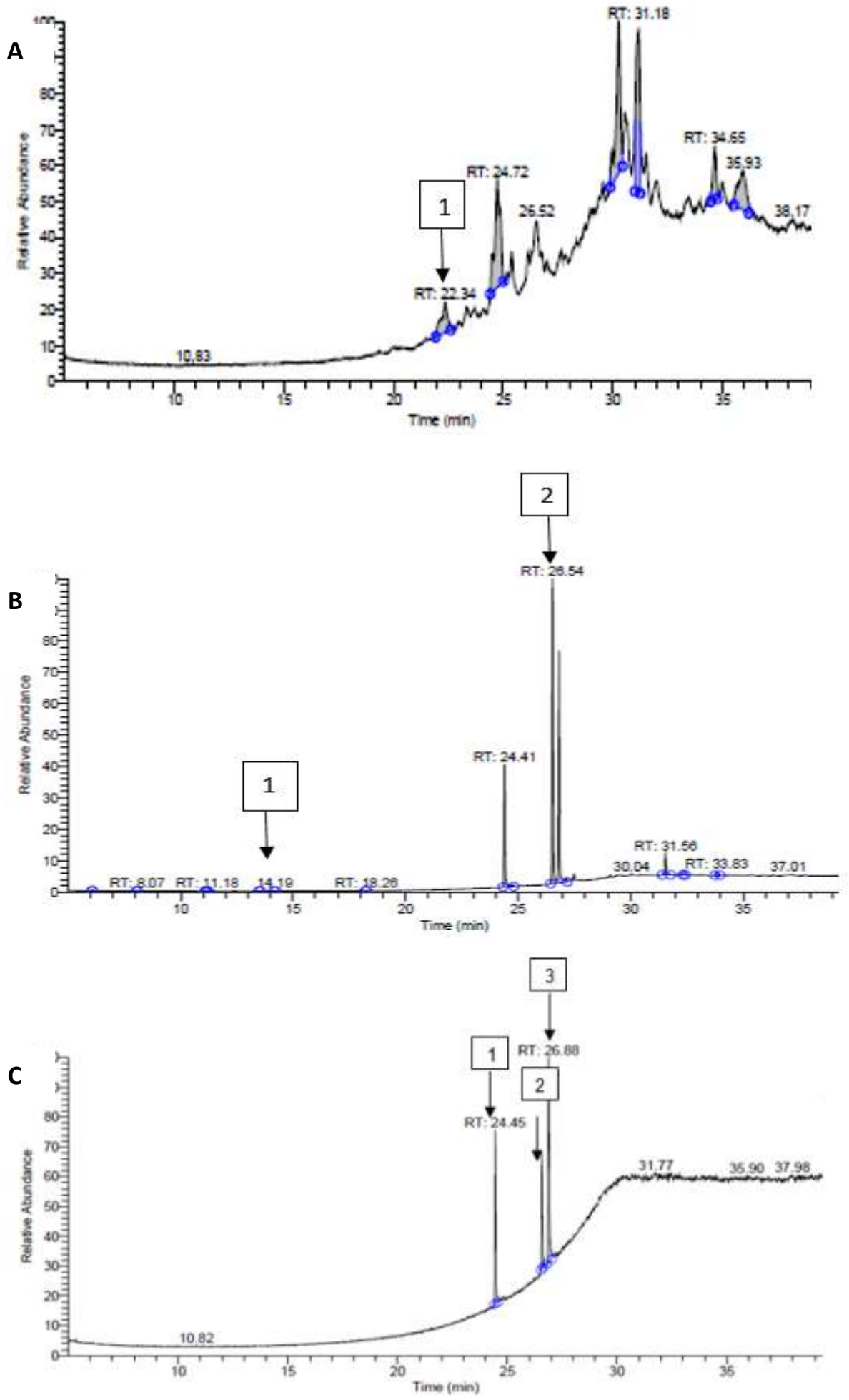


\section{DISCUSSION and CONCLUSION}

Isolation and purification of alkaloids are crucial for medical and chemical studies due to their bioactivity. This emphasizes the importance of protocols for alkaloid extraction from plants. In this study, total alkaloid extracts were obtained from three different protocols (preceding Soxhlet (A) and ultrasound (B) protocol and recommended modified Soxhlet protocol (C)) from G. corniculatum, a member of the Papaveraceae family. The alkaloid amount, purity and diversity in the extracts obtained were compared.

The Papaveraceae family is distinguished by the richness of their alkaloid contents (Almousawi \& Alwan, 2017). It has been shown in the literature that about 165 Papaveraceae species contain alkaloids (Preininger, 1985; Yu et al., 2014), and G. corniculatum is one of these species. More than 20 alkaloids have been identified from G. corniculatum extracts prepared with various solvents (Shafiee et al., 1985; Slavík \& Šantavý, 1972). Accordingly, G. corniculatum is a good source for total alkaloid extraction.

The main factors affecting the extraction efficiency and the amount and variety of bioactive compounds in the extract were the extraction protocol, duration, temperature and chemicals used. In the modified Soxhlet protocol, the plant was extracted in the Soxhlet apparatus for 8 hours and diethyl ether administration was carried out in three steps for greater separation of the oils, unlike Protocol A. In addition, increasing the amount of acid in the extraction process helped the alkaloid to decompose highly from other compounds. In the protocol, chloroform was preferred as organic solvent instead of dichloromethane (Kutchan, 1995). Thus, alkaloids in base form were obtained in a purer form. In the Soxhlet method, it was reported that the components passed to the solvent better than the ultrasonication method (Schmeck \& Wenclawiak, 2005). The most obvious advantage of using the Soxhlet method is that the sample phase repeatedly comes into contact with a new part of the solvent, thereby allowing the components to separate from the plant (Luque de Castro \& García-Ayuso, 1998). Our study also supported this data.

In Protocols A and B, higher amounts of extract were obtained compared to Protocol C; however, the alkaloid amount in the extract was lower than the amount obtained in Protocol C. This may be due to the fact that the amount of the extracts is higher than the amount in Protocol $\mathrm{C}$ because of the presence of other non-alkaloids in Protocols A and B. This may be associated with the presence of purer alkaloids with more variety in Protocol C.

Various methods with different sensitivities, such as gravimetric, titrimetric and spectrophotometric, have been developed for the determination of alkaloids in plant materials. However, gravimetric and titrimetric methods lack sufficient sensitivity. On the other hand, spectrophotometric determination of total alkaloids by bromocresol green is a simple and sensitive method and does not require any special equipment (Novelli et al., 2014). The highest amount of alkaloids were determined in $1 \mathrm{~g}$ extract and $1 \mathrm{~g}$ plant in Protocol $\mathrm{C}$ according to our data obtained by spectrophotometric analysis $(153 \pm 6 \mathrm{mg} / \mathrm{g}$ extract and $0.765 \mathrm{mg} / \mathrm{g}$ dry plant, respectively), and the total amount of alkaloids in $1 \mathrm{~g}$ dry plant, belonging to the Papaveraceae family, was found as 0.02-25 mg (Dittbrenner, 2009; Jimoh et al., 2010). According to these data, the total amount of alkaloids, obtained in Protocol C, was similar to the total amount of alkaloids obtained from different species in the same family.

Another method for the determination of alkaloids is chromatographic analysis. Since alkaloids appear in solutions in ionized and combined forms, chromatographic peaks of alkaloids are difficult to determine and have low system yields (Petruczynik, 2012). GC-MS is a useful and reproducible technique in eliminating this problem. This technique can be used to identify and quantify ionized compounds that have a low molecular weight in complex mixtures. In addition, GC-MS provides fast and reliable identification of compounds since 
spectra of compounds can be compared to library data (Järnberg et al., 1994; Villas-Bôas et al., 2005). Alkaloid content and diversity of extracts were determined by GC-MS method for the above reason.

A good alkaloid extraction protocol should not only give high alkaloid content, but also high alkaloid diversity. The number of alkaloids identified in these three different protocols and their ratios in the extract were different in qualitative GC-MS analyses. Only one alkaloid (7.6\%) was identified in the extract that is obtained in Protocol A, while two (92.4\%) alkaloids were identified in the extract obtained in Protocol B. Non-alkaloid compounds were identified in both the extracts. The extract that is obtained by the modified Soxhlet protocol (C), had no peaks other than three alkaloid peaks. These results proved that high purity and variety of alkaloids can be obtained using Protocol $\mathrm{C}$, the recommended extraction method. For this reason, Protocol $\mathrm{C}$ is a recommended method for alkaloid extraction from plants due to high extraction amount and advantages of a wide variety of alkaloids.

The study confirms that the proposed modified Soxhlet protocol is more efficient than previous Soxhlet and ultrasonication protocols for the extraction of alkaloids. This protocol is advantageous because it allows for obtaining greater amounts of extract, more diverse and purer alkaloids compared to other methods.

\section{Acknowledgments}

We thank the Scientific and Technological Research Council of Turkey (TUBITAK) for their financial support (Project no 116S299). The study has been previously presented at Black Sea Summit 6th International Applied Sciences Congress, Sinop, Türkiye, 05-06 June 2021.

\section{Declaration of Conflicting Interests and Ethics}

The authors declare no conflict of interest. This research study complies with research and publishing ethics. The scientific and legal responsibility for manuscripts published in IJSM belongs to the author(s).

\section{Authorship contribution statement}

Fatma Gonca Kocanci: Investigation, Resources, Visualization, Software, Formal Analysis, and Writing - original draft. Serap Nigdelioglu Dolanbay: Investigation, Resources, Visualization, Software, Formal Analysis. Belma Aslim: Methodology, Supervision, and Validation.

\section{Orcid}

Fatma Gonca Kocanci (iD https://orcid.org/0000-0002-7248-7933

Serap Nigdelioglu Dolanbay (D) https://orcid.org/0000-0002-1238-0894

Belma Aslim (iD https://orcid.org/0000-0002-0595-7237

\section{REFERENCES}

Almousawi, U.M.N., \& Alwan, A.A. (2017). The significance of opium alkaloids in the classification of Papaveraceae in Iraq. Journal of Pharmacognosy and Phytochemistry, 6(1), 430-437.

Amirkia, V., \& Heinrich, M. (2014). Alkaloids as drug leads - A predictive structural and biodiversity-based analysis. Phytochemistry Letters, 10. https://cyberleninka.org/article/n/1 019139

Chaves, K.M.S., M. Feitosa, C., \& da S. Araújo, L. (2016). Alkaloids Pharmacological Activities-Prospects for the Development of Phytopharmaceuticals for Neurodegenerative Diseases. Current Pharmaceutical Biotechnology, 17(7), 629-635. 
Cushnie, T.P.T., Cushnie, B., \& Lamb, A.J. (2014). Alkaloids: An overview of their antibacterial, antibiotic-enhancing and antivirulence activities. International Journal of Antimicrobial Agents, 44(5), 377-386. https://doi.org/10.1016/j.ijantimicag.2014.06.001

Demaggio, A.E., \& Lott, J.A. (1964). Application of Ultrasound for Increasing Alkaloid Yield from Datura Stramonium. Journal of Pharmaceutical Sciences, 53(8), 945-949. https://doi.org/10.1002/jps.2600530822

Desgrouas, C., Baghdikian, B., Mabrouki, F., Bory, S., Taudon, N., Parzy, D., \& Ollivier, E. (2014). Rapid and green extraction, assisted by microwave and ultrasound of cepharanthine from Stephania rotunda Lour. Separation and Purification Technology, 123, 9-14. https://doi.org/10.1016/j.seppur.2013.12.016

Dittbrenner A. (2009). Morphologische, phytochemische und molekulare Untersuchungen zur intraspezifi schen Diversität von Schlafmohn (Papaver somniferum L.). [PhD Thesis, Martin Luther University]. Halle-Wittenberg, Germany. http://dx.doi.org/10.25673/502

Doncheva, T., Kostova, N., Yordanova, G., Saadi, H., Akrib, F., Dimitrov, D., \& Philipov, S. (2014). Comparison of alkaloid profile from Glaucium corniculatum (Papaveraceae) of Algerian and Bulgarian origin. Biochemical Systematics and Ecology, 56, 278-280. https://www.cabdirect.org/cabdirect/abstract/20143390676

Hesse, M. (2002). Alkaloids: Nature's Curse Or Blessing? John Wiley \& Sons.

Järnberg, U., Asplund, L., \& Jakobsson, E. (1994). Gas chromatographic retention behaviour of polychlorinated naphthalenes on non-polar, polarizable, polar and smectic capillary columns. Journal of Chromatography A, 683(2), 385-396. https://doi.org/10.1016/00219673(94)00515-X

Jimoh, F., Adedapo, A., Aliero, A., \& Afolayan, A. (2010). Polyphenolic and biological activities of leaves extracts of Argemone subfusiformis (Papaveraceae) and Urtica urens (Urticaceae). Revista de Biología Tropical, 58(4), 1517-1531.

Kaya, G.I., Uzun, K., Bozkurt, B., Onur, M.A., Somer, N.U., Glatzel, D.K., \& Fürst, R. (2017). Chemical characterization and biological activity of an endemic Amaryllidaceae species: Galanthus cilicicus. South African Journal of Botany, 108, 256-260. https://doi.org/10.101 6/j.sajb.2016.11.008

Khamtache-Abderrahim, S., Lequart-Pillon, M., Gontier, E., Gaillard, I., Pilard, S., Mathiron, D., Djoudad-Kadji, H., \& Maiza-Benabdesselam, F. (2016). Isoquinoline alkaloid fractions of Fumaria officinalis: Characterization and evaluation of their antioxidant and antibacterial activities. Industrial Crops and Products, 94, 1001-1008. https://doi.org/10.1016/j.indcrop. 2016.09.016

Kintsurashvili, L.G., \& Vachnadze, V. Yu. (2000). Alkaloids ofGlaucium corniculatum andG. flavum growing in Georgia. Chemistry of Natural Compounds, 36(2), 225-226. https://doi. org/10.1007/BF02236441

Kutchan, T. M. (1995). Alkaloid Biosynthesis[mdash]The Basis for Metabolic Engineering of Medicinal Plants. The Plant Cell, 7(7), 1059. https://doi.org/10.1105/tpc.7.7.1059

Luque de Castro, M.D., \& García-Ayuso, L.E. (1998). Soxhlet extraction of solid materials: An outdated technique with a promising innovative future. Analytica Chimica Acta, 369(1), 110. https://doi.org/10.1016/S0003-2670(98)00233-5

Nigdelioglu Dolanbay, S., Kocanci, F. G., \& Aslim, B. (2021). Neuroprotective effects of allocryptopine-rich alkaloid extracts against oxidative stress-induced neuronal damage. Biomedicine \& Pharmacotherapy, 140, 111690. https://doi.org/10.1016/j.biopha.2021.111 $\underline{690}$

Novelli, S., Lorena, C., \& Antonella, C. (2014). Identification of Alkaloid's Profile in Ficus benjamina L. Extracts with Higher Antioxidant Power. American Journal of Plant Sciences, 05(26), 4029. https://doi.org/10.4236/ajps.2014.526421 
Petruczynik, A. (2012). Analysis of alkaloids from different chemical groups by different liquid chromatography methods. Open Chemistry, 10(3), 802-835. https://doi.org/10.2478/s11532012-0037-y

Phillipson, J.D., Gray, A.I., Askari, A.A.R., \& Khalil, A.A. (1981). Alkaloids From Iraqi Species of Papaveraceae. Journal of Natural Products, 44(3), 296-307. https://doi.org/10.1 021/np50015a011

Preininger, V. (1985). Chemotaxonomy of the Papaveraceae Alkaloids. Içinde J. D. Phillipson, M. F. Roberts, \& M. H. Zenk (Ed.), The Chemistry and Biology of Isoquinoline Alkaloids (ss. 23-37). Springer Berlin Heidelberg.

Sarikaya, B.B., Somer, N.U., Kaya, G.I., Onur, M.A., Bastida, J., \& Berkov, S. (2014). GC-MS Investigation and Acetylcholinesterase Inhibitory Activity of Galanthus rizehensis. Zeitschrift für Naturforschung C, 68(3-4), 118-124. https://doi.org/10.1515/znc-2013-3-407

Schmeck, T., \& Wenclawiak, B.W. (2005). Sediment Matrix Induced Response Enhancement in the Gas Chromatographic-Mass Spectrometric Quantification of Insecticides in Four Different Solvent Extracts from Ultrasonic and Soxhlet Extraction. Chromatographia, 62(3), 159-165. https://doi.org/10.1365/s10337-005-0589-5

Shafiee, A., Ghanbarpour, A., \& Akhlaghi, S. (1985). Alkaloids of Papaveraceae, XII. Alkaloids of Glaucium corniculatum subspecies Refractum, Population Pol-Dokhtar. Journal of Natural Products, 48(5), 855-856. https://doi.org/10.1021/np50041a037

Slavík, J., \& Šantavý, F. (1972). Alkaloids of the Papaveraceae. XLVII. Identity of bocconine with chelirubine. Collection of Czechoslovak Chemical Communications, 37(8), 2804-2806. https://doi.org/10.1135/cccc19722804

Villas-Bôas, S.G., Mas, S., Åkesson, M., Smedsgaard, J., \& Nielsen, J. (2005). Mass spectrometry in metabolome analysis. Mass Spectrometry Reviews, 24(5), 613-646. https://doi.org/10.1002/mas.20032

Webster, G.R.B. (2006). Soxhlet and Ultrasonic Extraction of Organics in Solids. Içinde Encyclopedia of Analytical Chemistry. American Cancer Society. https://doi.org/10.1002/9 780470027318.a0864

Yu, H.-H., Kim, K.-J., Cha, J.-D., Kim, H.-K., Lee, Y.-E., Choi, N.-Y., \& You, Y.-O. (2005). Antimicrobial Activity of Berberine Alone and in Combination with Ampicillin or Oxacillin Against Methicillin-Resistant Staphylococcus aureus. Journal of Medicinal Food, 8(4), 454461. https://doi.org/10.1089/jmf.2005.8.454

Yu, X., Gao, X., Zhu, Z., Cao, Y., Zhang, Q., Tu, P., \& Chai, X. (2014). Alkaloids from the tribe Bocconieae (papaveraceae): A chemical and biological review. Molecules (Basel, Switzerland), 19(9), 13042-13060. https://doi.org/10.3390/molecules190913042 